\title{
PERFORMANCE EVALUATION AND MODIFICATION OF SHREDDER CUTTING MECHANISM
}

\author{
N. SRIDHAR ${ }^{1} \&$ A. SURENDRAKUMAR ${ }^{2}$ \\ ${ }^{I}$ Research Scholar, Department of Farm Machinery and Power, AEC \& RI, \\ Tamil Nadu Agricultural University, Kumulur, Trichy, Tamil Nadu, India \\ ${ }^{2}$ Professor, Department of Farm Machinery, AMRC, Tamil Nadu \\ Agricultural University, Coimbatore, Tamil Nadu, India
}

\begin{abstract}
In order to aid in engineering design and modification of cutting mechanism in shredders, and to investigate the effect of parameter on cutting energy, an impact type pendulum test rig was used to measure the energy required for cutting the plant stems. A total number of 324 experiments were carried out on $\mathrm{KC}_{1}$ cotton variety, in different thickness viz., $6\left(T_{1}\right), 8\left(T_{2}\right)$ and $10\left(T_{3}\right) \mathrm{mm}$, approach angle viz., $0\left(\varphi_{1}\right), 15\left(\varphi_{2}\right)$, and $30\left(\varphi_{3}\right)$ deg, shear angle viz., $0\left(\theta_{1}\right), 15\left(\theta_{2}\right)$ and $20\left(\theta_{3}\right)$ deg and bevel angle of cutter blade viz., $23\left(\alpha_{1}\right), 25\left(\alpha_{2}\right), 28\left(\alpha_{3}\right)$ and $30 \mathrm{deg}\left(\alpha_{4}\right)$. The results show that the optimum value of Specific Cutting Energy (SCE) $178.04 \mathrm{~J}$ was obtained, at treatment combination level of $\alpha_{2} \times T_{3} \times \theta_{1} \times \varphi_{2}$, respectively. The optimized treatment combination has been selected, for modifying the cutting mechanism of selected shredder. The modified shredder, evaluated in actual field condition resulted in saving 37.5 and 82 percent cost and time, when compared with conventional method of crop residue removal, from agricultural field.
\end{abstract}

KEYWORDS: Angle of Cutting, Pendulum Test Rig, Field Efficiency \& Shredding Efficiency

Received: Jul 24, 2017; Accepted: Aug 12, 2017; Published: Sep 19, 2017; Paper Id.: IJASROCT201728

\section{INTRODUCTION}

Govt. Of India estimates, approximately $500 \mathrm{Mt}$ of crop residues are generated every year (MNRE, 2009). According to different estimates, 72 Mt-127 Mt of crop residues are burnt on-farm (Mehta, 2004; Pathak et al., 2006; Pathak et al., 2010). Burning residues leads to a plethora of problems, such as the release of soot particles and smoke causing human health problems, emission of greenhouse gases, such as carbon dioxide, methane and nitrous oxide adding to global warming and loss of plant nutrients, such as N, P, K and S. Niveta Jain et al (2014) reported burning of 98.4 Mt crop residues emitted 8.57 Mt of CO, 141.15 Mt of CO2, 0.037 Mt of SOx, 0.23 Mt of NOx, 0.12 Mt of NH3 and 1.46 Mt NMVOC, 0.65 Mt of NMHC, 1.21 Mt of particulate matter, during the year 2008-09. Instated of burning, retention on of crop residues on field surface, which help to conserve moisture, nutrients and controlling weeds in addition to moderating soil temperature. Rajendra Reddy et al. (2002) conducted a study, to find out the effect of crop residues and tillage operations, on the physico- chemical and microbial properties of soil and the crop performance. It was found that, the incorporation of crop residue like wheat straw about $5 \mathrm{tha}^{-1}$ resulted $^{-1}$ in improved soil physical characteristics (bulk density decreased from 1.29 to $1.26 \mathrm{mg} \mathrm{m}^{-3}$, infiltration rate and hydraulic conductivity increased from 2.42 to $2.86 \mathrm{~cm} \mathrm{hr}^{-1}$ ), along with increased nutrient status (available nitrogen increased from 160.9 to $221.2 \mathrm{~kg} \mathrm{ha}^{-1}$, phosphorous increased from 16.2 to $21.2 \mathrm{~kg} \mathrm{ha}^{-1}$ and potassium increased from 320.8 to $429.8 \mathrm{~kg}$ $\mathrm{ha}^{-1}$ ).In India, mostly the plants are removed by manual pulling or cutting by sickle, up to the height of 50 to $75 \mathrm{~mm}$ above the ground surface and burnt later. Non-availability of labor, troubles of mechanization and high cost of residue 
removal from the field crops, are some of main reasons behind burning of crop residues. Shredders are most commonly used, for removing the crop residues from agricultural field. Shredding of crop can be performed in a short span of time, which is of great advantage, especially in the early decomposition of the crop residue in field, to increase soil nutrient content. The performance of each shredder differs depending on many factors viz,. thickness of cutter blade, bevel angle, shear angle, approach angle of cutter blade, peripheral velocity of cutter blade and forward speed of operation. Design a new shredder, or modification of the cutting mechanisms of shredder needs new engineering data, on the cutting properties of crop stem. Determination of specific cutting energy, is considered to be an important criterion for comparing the effectiveness of any cutting system. Prasad and Gupta (1975), investigated the mechanical properties of maize stalk, as related to harvesting in a pendulum impact test apparatus. They reported that, the specific cutting force for maize stalk was $6.3 \mathrm{~N} \mathrm{~mm}^{-1}$, while studying the rheological properties of maize stalk under transverse loading, they found that, the optimal value of 23 deg for the bevel angle and $55 \mathrm{deg}$ for shear angle and $2.65 \mathrm{~m} \mathrm{~s}^{-1}$ for cutting velocity. The minimum cutting energy was $17 \mathrm{MJ}$ $\mathrm{mm}^{-2}$ for maize stalk, at 73.6 percent moisture content on a wet basis. Persson (1987) reported that, impact on cutting the energy consumed to overcome the shearing resistance of the stem, is equal to the energy required for quasi-statics cutting, plus the energy expended in overcoming friction. Imbabi (1992) found that, the energy requirements for cutting the sesame plants ranged from 4.32 to 27.03 Joule stem $^{-1}$, according to the moisture content of stems, while the cutting force ranged from 432.14 to $1351.31 \mathrm{~N} \mathrm{stem}^{-1}$, according to the moisture content of stems. The energy required for the cutting unit of stalk cutter, may be categorized as: friction in the moving parts of the machine and air friction; kinetic energy required to accelerate the chopped material; energy required to overcome friction of the chopped material, against the stationary parts of machine; and energy required to cut the stalk (O’Dogherty et al., 1995; Chattopadhyay and Pandey, 1999).The cutting strength of the plant stem, and effective parameters on cutting energy have been reported by many researchers, such as rice ( Lee and and Huh 1984), wheat (Hoseinzadeh et al., 2009; Esehaghbeygi et al., 2009; Muller, 1988), barely (Tavakoli et al., 2009), potato vines (Godesa, 2004), soya bean (Mesquita and Hanna, 1995) and alfalfa (Nazari Galedar et al., 2008). Reza (2007) designed and constructed a pendulum type impact shear test apparatus, for measuring the energy required for cutting paddy stem, and optimized the blade optimum parameters. The optimized blade parameters were 28 deg blade bevel angle, 30 deg oblique angle (approach angle), 35 deg tilt angle (shear angle) and $2.24 \mathrm{~ms}^{-1}$ peripheral velocity of blade. Yumnam Jekendra and Pratap Singh (1991) concluded that, the rake angle (approach angle) of 10 to 20 deg and operating speed between 25 to $35 \mathrm{~ms}^{-1}$, gives an optimum cutting energy requirement for forage chopping. $\mathrm{O}$ 'Dogherty and Gale (1986), investigated the effect of blade parameters on the dynamics of cutting grass. They have used blade thickness of 1 to $3 \mathrm{~mm}$, in blunt condition. The results showed that, below the critical speed $\left(35 \mathrm{~ms}^{-1}\right)$ both cutting time and distance were significantly less, for the $1 \mathrm{~mm}$ blade than for the 2 and $3 \mathrm{~mm}$ blades. Vagadia et al. (2004) developed an agricultural waste shredder, with the size of blade of $362 \times 80 \times 11 \mathrm{~mm}$. One side of the blade was sharpened and the edge was made $30 \mathrm{deg}$ beveled, for smooth cutting. Senthilkumar (2004) developed a cotton stalk shredder, cum in situ applicator, with the combination of 2 number of blades, $28.60 \mathrm{~ms}^{-1}$ peripheral velocity, $6 \mathrm{~mm}$ blade thickness (model) and 0 deg rake angle was selected, for experimental cotton stalk shredder for prototype 2 number of blades, 0 deg rake angle and $12 \mathrm{~mm}$ blade thickness was selected. Morad and Fouda (2009) reported that, the forward speeds between 4 to $5.5 \mathrm{~km} \mathrm{~h}^{-1}, 2.8$ to $4.8 \mathrm{~km} \mathrm{~h}^{-}$ ${ }^{1}$ and 2.1 to $3.2 \mathrm{~km} \mathrm{~h}^{-1}$ were recommended for removing rice straw, cotton stalks and sunflower stalks, respectively. Maughan et al. (2012) investigated the impact of cutting speed, blade type, and blade angle on miscanthus harvesting energy requirement. The cutting energy was determined at three cutting speeds $\left(31.5,47.3\right.$ and $\left.63.0 \mathrm{~m} \mathrm{~s}^{-1}\right)$, three oblique angles (approach angle) (0,30 and $40 \mathrm{deg}$ ) and two blade fixtures (fixed, flexible). The differences between the blade 
fixtures were found to be negligible. A 40 deg oblique angle, operating at $31.5 \mathrm{~ms}^{-1}$ had the lowest energy consumption, averaging $9.1 \mathrm{MJ} \mathrm{ha}^{-1}$.

Information on physical and mechanical characteristics of plant, and the power or energy requirement of equipment, has been very valuable for selecting a design and operational parameters of the equipment Persson, (1987). Such information is needed, for the design of shredding and other agricultural machineries, assuring appropriate machine functions and an efficient use of energy.

The specific objectives of the present study were,

- To study the effect of blade parameters and to determine their optimum values for modification of the cutting mechanism.

- To investigate the shredding efficiency of modified shredder based on optimized values.

\section{MATERIALS AND METHODS}

The efficiency of shredder is the ability to cut the crop stalk into very small pieces. The impact type rotary cutter performance, mainly depends on the design of cutting mechanism of rotating blades. Many factors were involved in the design of rotary cutter blades. The most significant features of the rotating blades are, thickness of cutter blade, bevel angle, shear angle, approach angle of cutter blade, peripheral velocity of cutter blade and forward speed of operation. For achieving maximum shredding efficiency of crop stalks, the following variables were selected for the investigation.

- Bevel angle of cutter blade

- Shear angle of cutter blade

- Approach angle of cutter blade

- Thickness of cutter blade

A total number of 324 experiments were conducted, in Department of farm power and machinery, AEC\&RI, Tamil Nadu agricultural University, Coimbatore, by using the impact type pendulum test rig, as shown in Plate 1 . The $\mathrm{KC}_{1}$ (H) variety cotton stem was selected, for the entire laboratory experiment. The investigation was carried out, with four levels of bevel angle viz., 23, 25, 28 and $30 \mathrm{deg}$, three levels of approach angle 0,15 , and $30 \mathrm{deg}$, three levels of shear angle 0,15 , and $20 \mathrm{deg}$, and three levels of thickness of the cutter blade $6 \mathrm{~mm}, 8 \mathrm{~mm}$ and $10 \mathrm{~mm}$, respectively. The moisture content of cotton stalk was maintained constant (42 to 53.23 per cent in dry basis) throughout all experiments. The specific cutting energy for selected cotton stem was recorded, during the lab investigation. The effect of selected levels of variables, for the evaluation parameters was analyzed using a completely randomized design.

\section{Principle of Operation of Pendulum Test Rig}

The working principle of impact, type pendulum test rig, where a long swing arm suspended at its top end and has a blade fixed at the lower end is made to oscillate, in a vertical plane. It is normally displaced to one side of the equilibrium position, by an angular deflection ' $\theta$ '. By the principle of conservation of energy, the swing arm, when released is expected to oscillate to the other side of equilibrium line, and deflection through an angle ' $\theta$ '. There is a continuous exchange of energy of the swing arm, from maximum potential energy (when the arm is at its extreme upswing position before it is released to swing down) to maximum kinetic energy (when the swing arm is at the equilibrium line). The material to be cut is normally placed at the point 
of maximum kinetic energy, of the swinging arm and held by a material holder. When the swing arm is released, it gains speed till it contacts, and cuts the material placed in the path of the blade (koloor and Kiani, 2007; Johnson et al., 2012; Yiljep and Mohammed, 200).

\section{Cutting Energy Calculation}

The cutting energy of the stem was determined, by the difference between $\theta$ and $\theta_{0}$. Expressions for determining cutting energy requirement and peripheral knife speed, were given as stated by Prasad and Gupta (1975). The following formula has been used, for calculating specific cutting energy during the experiment.

$$
\mathrm{E}=\mathrm{MgR}\left(\cos \theta_{0}-\cos \theta\right)
$$

Where,

$\mathrm{E}=$ Energy utilized for cutting the pendulum, Joules

$\mathrm{M}=$ Mass of the pendulum, $(\mathrm{kg})$

$\mathrm{R}=$ Distance between the center of rotation and the center of gravity of the pendulum arm, $\mathrm{m}$

$\theta_{0}=$ Maximum angle of deflection on the pendulum frame from vertical after cutting the specimen, (deg)

$\theta=$ Maximum angle of deflection of the pendulum from vertical at the end of free swing, (deg)

\section{Optimization of Variables}

The selected levels of a variable have optimized, with respect to minimum specific cutting energy, for modification of the cutting mechanisms of selected shredder. The quality of cut was done by selecting treatment combination, as shown in Plate 1.

\section{Modification of Cutting Mechanism of Shredder}

The optimized value has been used, for modification of the cutting mechanisms of selected shredder. Hence, the tractor had been chosen, as the prime mover for work and the modified Shredder. It has been proposed to mount on the rear of the tractor, to complete the shredding operation. The schematic drawing of the tractor operated, modified Shredder and internal components of shredder, as shown in Figure 1 and Plate 2. The technical specifications of tractor operated modified shredder, as furnished in Table 1.

Table 1: Technical Specifications of Modified Shredder

\begin{tabular}{|c|l|c|}
\hline SI. No & \multicolumn{1}{|c|}{ Item } & Values \\
\hline A & Prime mover & $45 \mathrm{hp}$ tractor \\
\hline B & Over all dimensions $(\mathrm{L} \times \mathrm{B} \times \mathrm{H}), \mathrm{mm}$ & $1400 \times 1340 \times 840$ \\
\hline C & Cutter blade & Rotary impact type \\
\hline i. & Type of cutter & 6 \\
\hline Ii & Number of cutter blades & 25 \\
\hline Iii & Bevel angle of cutter blade, deg & 0 \\
\hline Iv & Shear angle of cutter blade, deg & 15 \\
\hline v. & Approach angle of cutter blade, deg & 10 \\
\hline Vi & Thickness of cutter blade, $\mathrm{mm}$ & 27.8 \\
\hline Vii & Rotary speed of cutter blade $\mathrm{m} \mathrm{s}^{-1}$ & 2 \\
\hline viii & Forward speed of operation $\mathrm{km} \mathrm{h}^{-1}$ & \\
\hline D & Type of power drive & PTO \\
\hline
\end{tabular}




\begin{tabular}{|c|l|l|}
\hline $\mathbf{E}$ & Power transmission for cuter blade & Through gear box \\
\hline
\end{tabular}
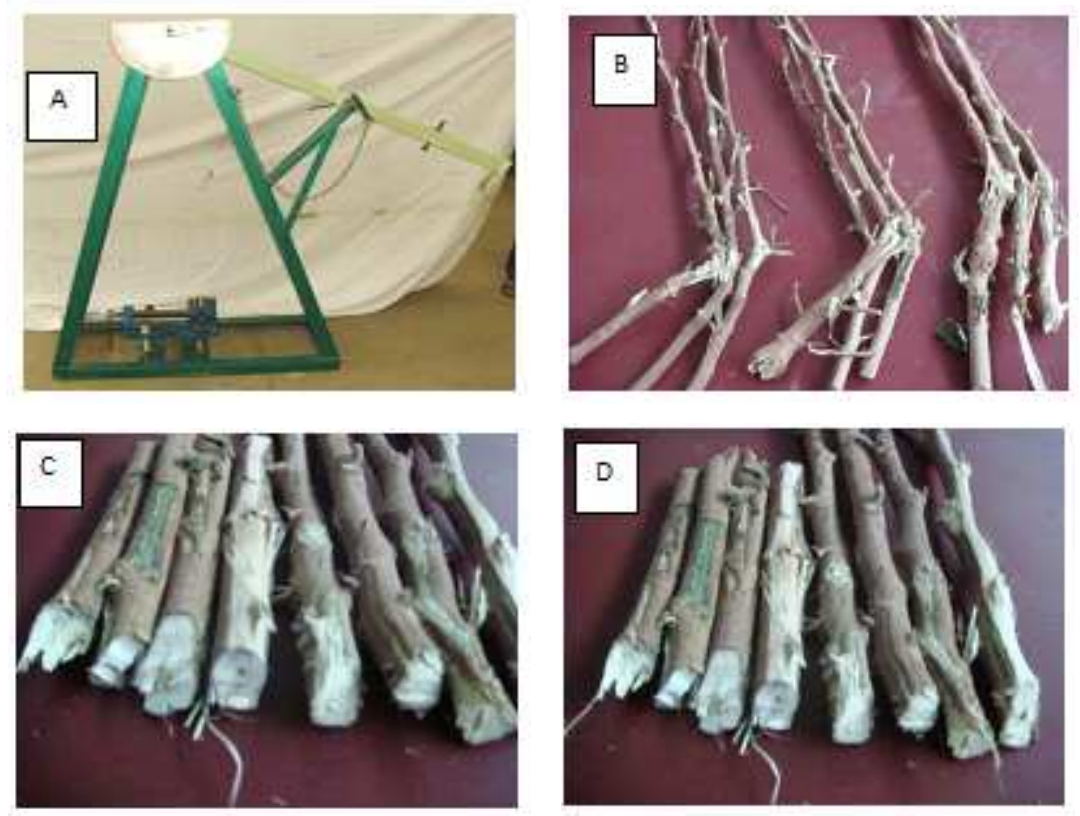

Plated 1: A = Impact Type Pendulum Test Rig, B Indicates Improper Cut and Indicates Proper Cut by Selected Treatment Combination
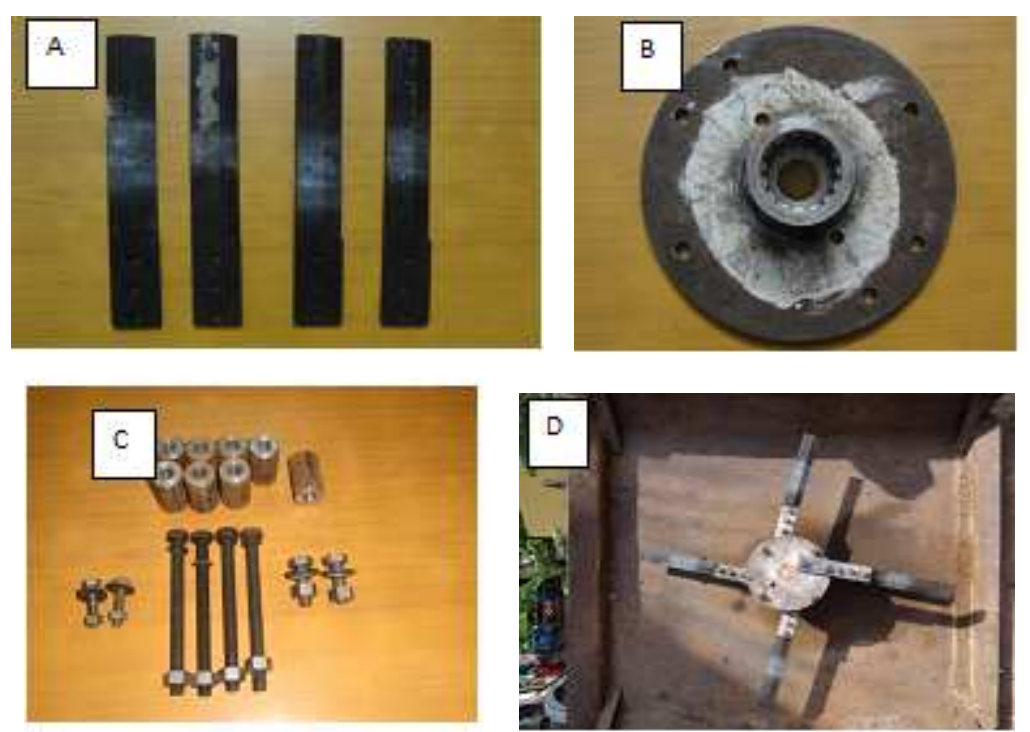

Plate 2: Internal Components of Modified Shredder (A= Cutting Knife, B= Circular Disc C= Bush, Nut and Bolt $D=$ Cutting Knife Assembly 

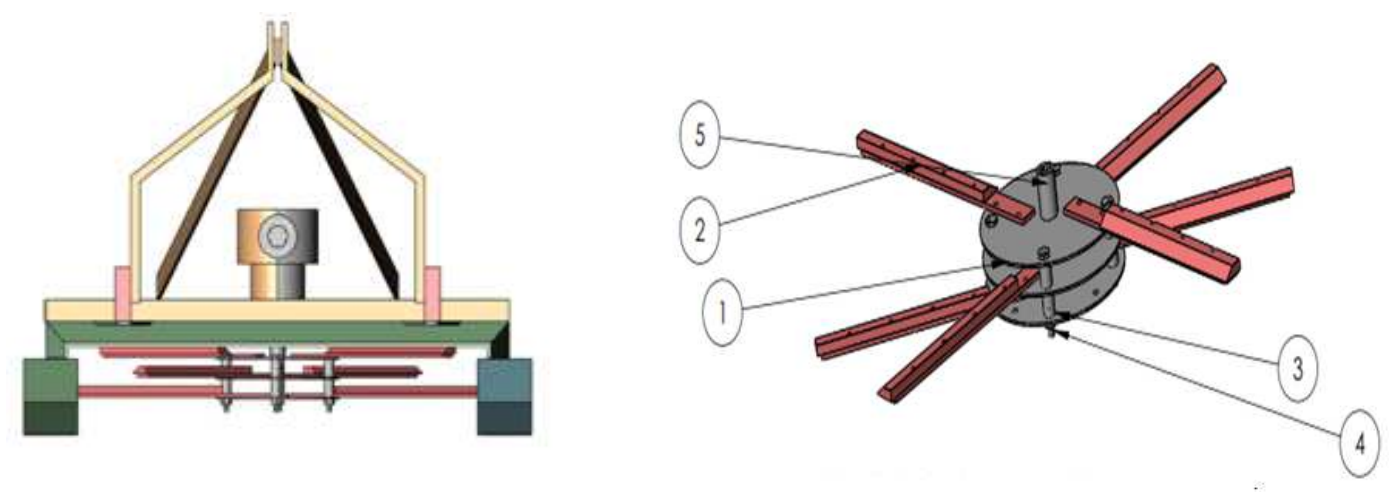

Figure 1: Modified Shredder Based on Optimized Values

\section{Components of Shredding Assembly}

\begin{tabular}{|c|l|c|}
\hline ITEM NO. & \multicolumn{1}{|c|}{ DESCRIPTION } & QTY. \\
\hline 1 & Circular Disc - Made up of MS Plates & 3 \\
\hline 2 & Cutter Blade - Made up of Soring Steel & 6 \\
\hline 3 & Bush - Made up of MS & 8 \\
\hline 4 & Bolt and Nuts - Made up of MS & 4 \\
\hline 5 & Input Shaft - Made up of EN8 & 1 \\
\hline
\end{tabular}

Figure 2: Blade Assembly of prototype

\section{Performance Evaluation of Modified Tractor Operated Shredder}

The modified tractor operated shredder was evaluated in actual field condition, in terms of shredding efficiency, field capacity and cost of operation. After the completion of shredding, the sample had been collected randomly, in shredded field. The collected samples have been measured by different scale level (referred to Luis et.al, 1993; Church 1991), according to their length viz., $0-5 \mathrm{~cm}, 5-10 \mathrm{~cm}, 10-15 \mathrm{~cm}, 15-20 \mathrm{~cm},>20 \mathrm{~cm}$, respectively.

\section{RESULTS AND DISCUSSIONS}

The three replications were taken from a different cross sectional area of cotton stem. The dial showed the indicated angle, for cutting cotton stem and corresponding cutting energy were calculated, using a formula.

\section{Effect of Approach Angle of Cutter Blade ( $\varphi)$ on Specific Cutting Energy}

The effect of approach angle $(\varphi)$ of cutter blade, on specific cutting energy at 0 deg $\left(\theta_{1}\right), 15 \mathrm{deg}\left(\theta_{1}\right)$ and $30 \mathrm{deg}$ $\left(\theta_{1}\right)$ shear angle, with bevel angle and thickness $(\mathrm{T})$ of cutter blade are shown in Figure 2.

In general, increase in approach angle from $0\left(\varphi_{1}\right)$ to $15\left(\varphi_{2}\right)$ deg, reduced the specific cutting energy, as well as increase in approach angle up to $30 \mathrm{deg}\left(\varphi_{3}\right)$, increased the specific cutting energy of cuter blade, respectively. When the cutter blade approach angle was higher at $30 \mathrm{deg}\left(\varphi_{3}\right)$, sliding of cutter blade occurred, which in turn reduced the impact effect of the blade and hence, higher specific cutting energy is required. The cutter blade with 15 deg $\left(\varphi_{2}\right)$ approach angle, yielded minimum specific cutting energy for selected levels of shear angle, bevel angle with $6\left(\mathrm{~T}_{1}\right), 8\left(\mathrm{~T}_{2}\right)$ and $10 \mathrm{~mm}\left(\mathrm{~T}_{3}\right)$ thickness of the cutter blades. This is in close agreement with the results, reported by El-Sahar 1988 and Sumner et.al $1984 a$. 


\section{Effect of Shear Angle of Cutter Blade ( $\theta)$ on Specific Cutting Energy}

The effect of shear angle $(\theta)$ deg, bevel angle $(\alpha)$ deg and thickness $(T) \mathrm{mm}$, of cutter blade on specific cutting energy at $0\left(\varphi_{1}\right)$ deg, $15\left(\varphi_{2}\right)$ deg and $30\left(\varphi_{3}\right)$ deg, approach angle is shown in Figure 3.

It is inferred that, there was a reduction of specific cutting energy, with increase in shear angle from 0 deg $\left(\theta_{1}\right)$ to $15 \mathrm{deg}\left(\theta_{2}\right)$. Increase in shear angle from $0\left(\theta_{1}\right)$ to $15\left(\theta_{2}\right)$ deg of cutter blade, has led to a reduction of frictional force of crop stem under impact and hence, reduced specific cutting energy (impact energy). Further increase of shear angle to 20 $\left(\theta_{3}\right) \mathrm{deg}$, resulted in an increasing of specific cutting energy, for bevel angle $23\left(\alpha_{1}\right), 25\left(\alpha_{2}\right), 28\left(\alpha_{3}\right)$ and $30\left(\alpha_{4}\right)$, with 6 $\left(\mathrm{T}_{1}\right), 8\left(\mathrm{~T}_{2}\right)$ and $10\left(\mathrm{~T}_{3}\right) \mathrm{mm}$ thickness of cutter blade, respectively. This might be due to the fact that, the plane of least resistance coincides with optimal value of shear angle of $20 \mathrm{deg}\left(\theta_{3}\right)$.

\section{Effect of Blade Thickness on Specific Cutting Energy}

The thickness of blade affects the specific cutting energy and shredding efficiency of the shredder (Bosoi et al., 1990). The effect of shear angle $(\theta)$ deg, bevel angle $(\alpha)$ deg and approach angle $(\varphi)$ deg of cutter blade, on specific cutting energy, with respect to the thickness of cutter blade $(\mathrm{T}) \mathrm{mm}$ is shown in Figure 4.

It is observed that, the cutting energy increases with increase in bevel angle $(\alpha)$ deg, approach angle $(\varphi)$ deg and shear angle $(\theta)$ deg but decreases with increase of the thickness of cutter blade (T) mm. Hence, the bevel angle, shear angle and approach angle should be kept at minimum, with maximum thickness $10 \mathrm{~mm}\left(\mathrm{~T}_{3}\right)$ of cutter blade resulted in minimum specific cutting energy required for cutting the crop stem.
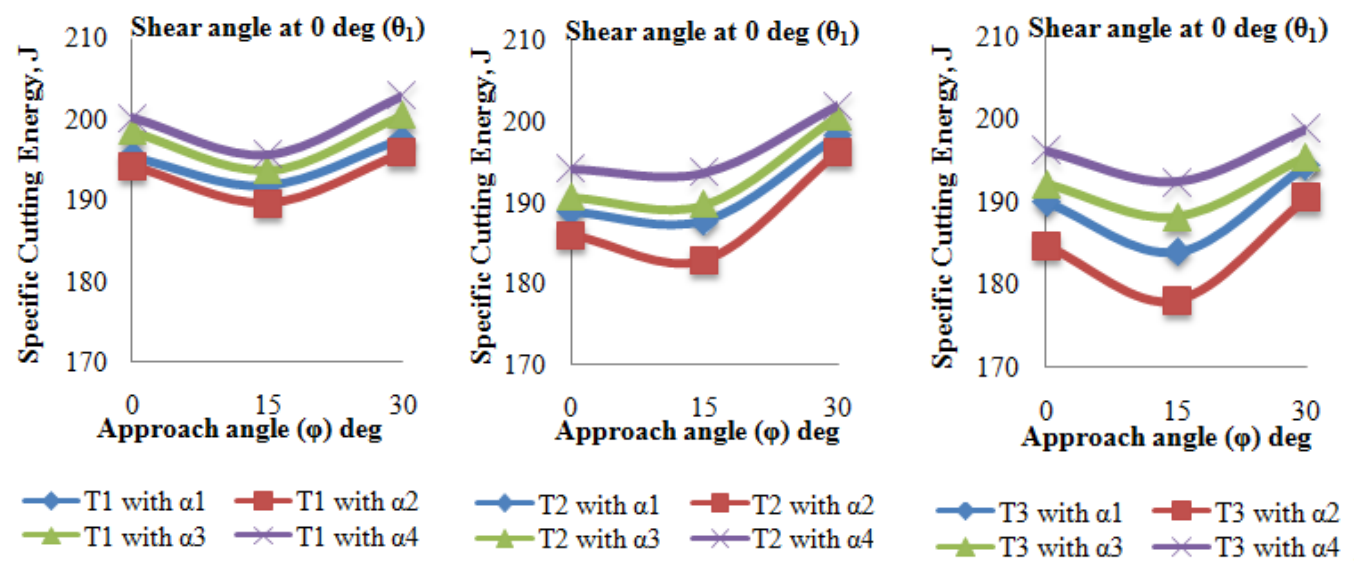

Figure 3(1): Effect of Approach Angle ( $\varphi$ ) Deg of Cutter Blade on Specific Cutting Energy for Cotton Stem at 0 Deg $\left(\theta_{1}\right)$ Shear Angle with Respect to Bevel Angle $(\alpha)$ and Thickness of Cutter Blade (T) 

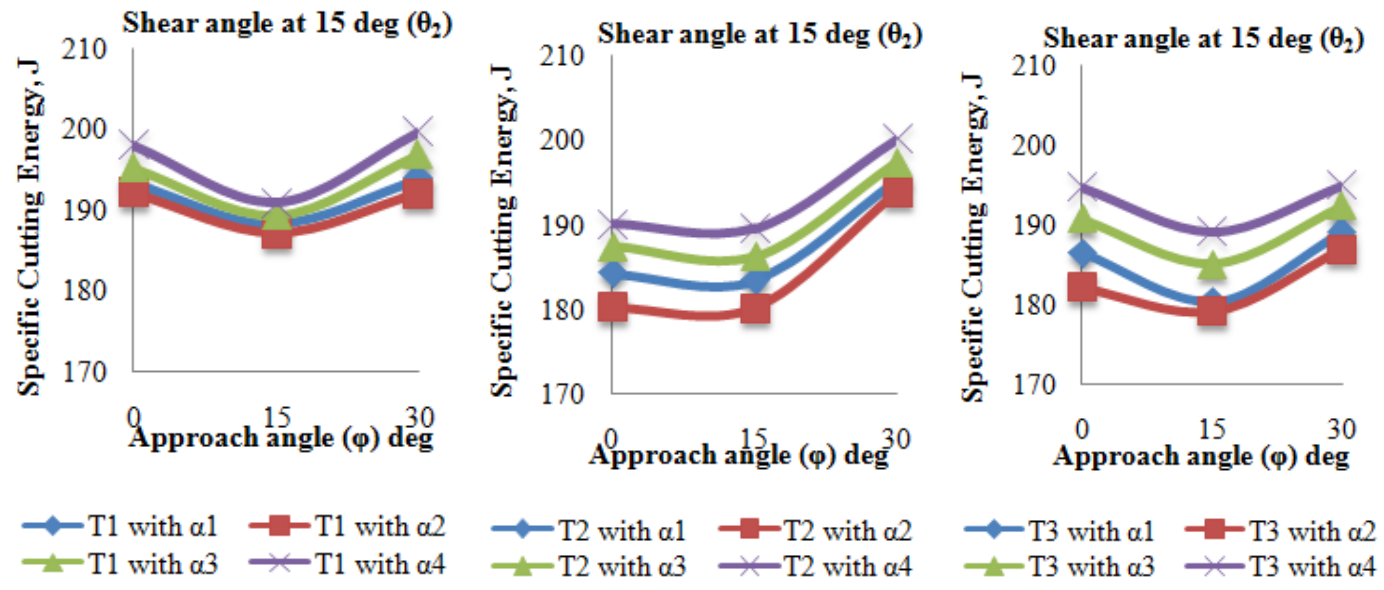

Figure 3(2): Effect of Approach Angle ( $\varphi$ ) Deg of Cutter Blade on Specific Cutting Energy for Cotton Stem at 15 Deg $\left(\theta_{2}\right)$ Shear Angle, with Respect to Bevel Angle ( $\left.\alpha\right)$ and Thickness of Cutter Blade (T)
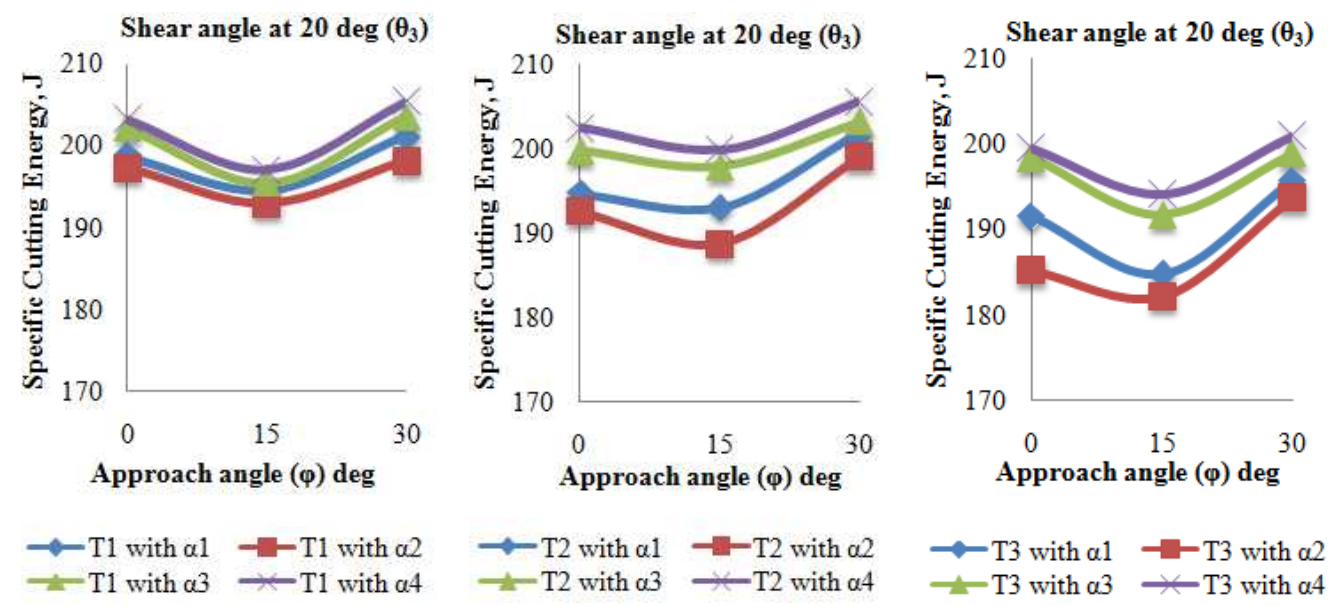

Figure 3(3): Effect of Approach angle ( $\varphi$ ) Deg of Cutter Blade on Specific Cutting Energy for Cotton Stem at 20 Deg $\left(\theta_{3}\right)$ Shear Angle with Respect to Bevel Angle $(\alpha)$ and Thickness of Cutter Blade (T)
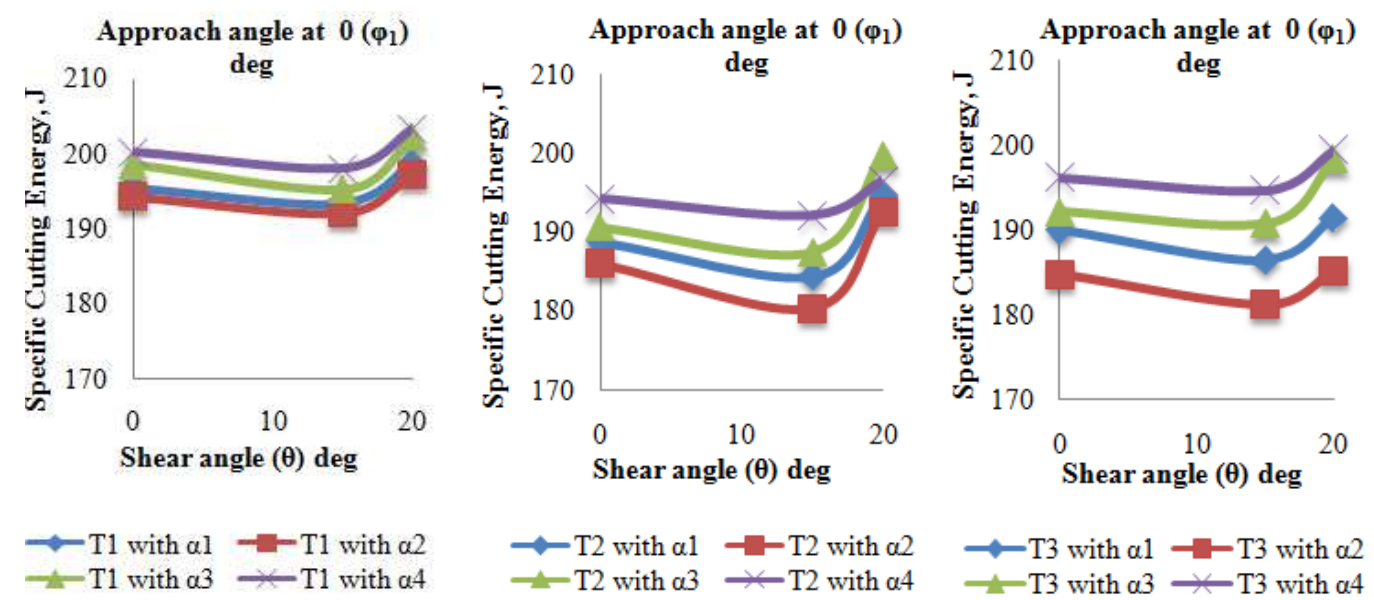

$-\mathrm{T} 3$ with $\alpha 1-\mathrm{T} 3$ with $\alpha 2$
$-\mathrm{T} 3$ with $\alpha 3 \longrightarrow \mathrm{T} 3$ with $\alpha 4$

Figure 4(1): Effect of Shear Angle ( $\theta)$ Deg of Cutter Blade on Specific Cutting Energy for Cotton Stem at 0 Deg $\left(\varphi_{1}\right)$ Approach Angle with Respect to Bevel Angle $(\alpha)$ and Thickness of Cutter Blade from $(T)$ 


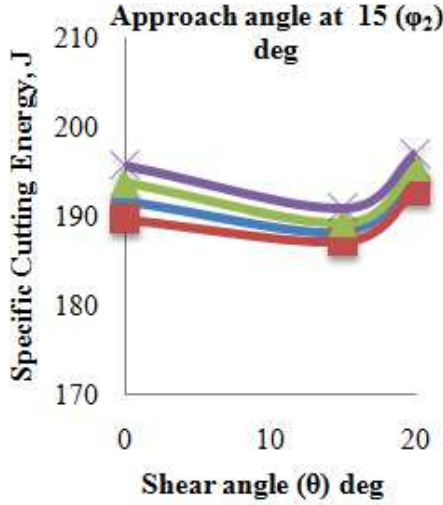

$\longrightarrow \mathrm{T} 1$ with $\alpha 1-\mathrm{T} 1$ with $\alpha 2$
$-\mathrm{T} 1$ with $\alpha 3 \rightarrow \mathrm{T} 1$ with $\alpha 4$
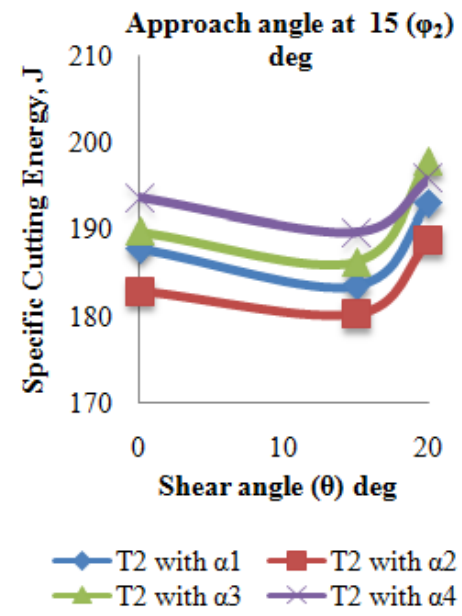

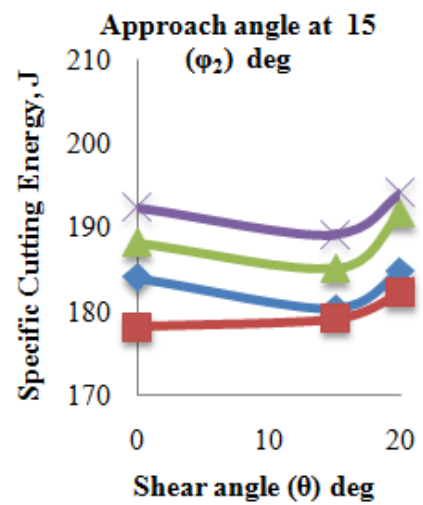

$\longrightarrow \mathrm{T} 3$ with $\alpha 1 \multimap \mathrm{T} 3$ with $\alpha 2$
$-\mathrm{T} 3$ with $\alpha 3 \longrightarrow \mathrm{T} 3$ with $\alpha 4$

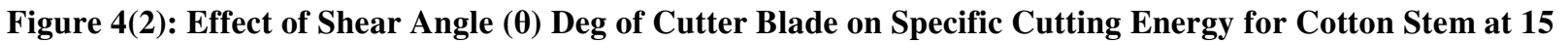
Deg $\left(\varphi_{2}\right)$ Approach Angle with Respect to Bevel Angle $(\alpha)$ and Thickness of Cutter Blade from (T)

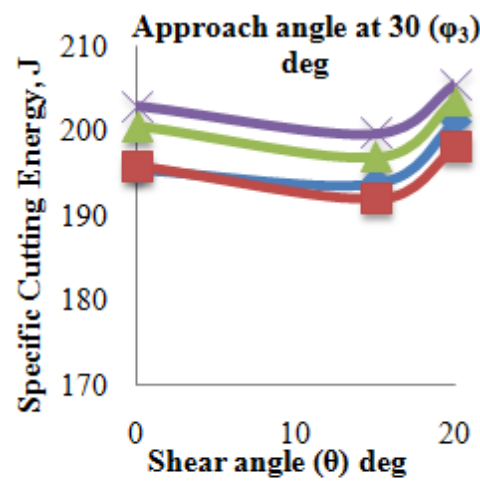

$\longrightarrow \mathrm{T} 1$ with $\alpha 1 \multimap \mathrm{T} 1$ with $\alpha 2$
$-\mathrm{T} 1$ with $\alpha 3 \longrightarrow \mathrm{T} 1$ with $\alpha 4$
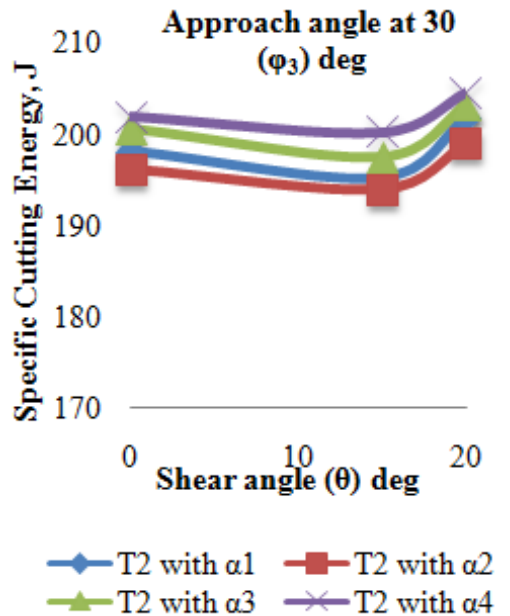

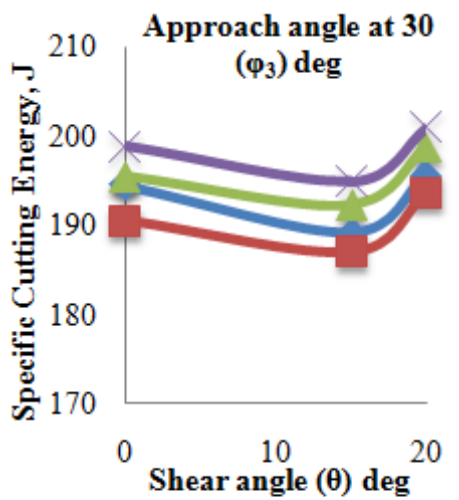

$\longrightarrow \mathrm{T} 3$ with $\alpha 1 \multimap \mathrm{T} 3$ with $\alpha 2$
$-\mathrm{T} 3$ with $\alpha 3 \rightarrow \mathrm{T} 3$ with $\alpha 4$

Figure 4(3): Effect of Shear Angle (日) Deg of Cutter Blade on Specific Cutting Energy for Cotton Stem at 30 Deg $\left(\varphi_{2}\right)$ Approach Angle, with Respect to Bevel Angle ( $\left.\alpha\right)$ and Thickness of Cutter Blade from (T)

\section{Effect of Bevel Angle of Cutter Blade $(\alpha)$ on Specific Cutting Energy}

Bevel angle significantly affects the specific reaction force and energy (Jelani et.al, 1999). The effect of shear angle $(\theta)$, approach angle $(\varphi)$ and thickness $(T)$ of cutter blade on specific cutting energy, with respect to a bevel angle $(\alpha)$ is shown in Figure 5.

In general, the force and energy required for cutting only increases, when the fineness exceeds a bevel angle of 30 deg. The most efficient fineness is at bevel angle of $24 \mathrm{deg}$, if any angle smaller than 24 deg resulted in rapid wear and dulling of the blade (Chacellor, 1958). From the above observation, it shows that, there is no more variation of specific cutting energy reduced, when the bevel angle increased from $23\left(\alpha_{1}\right)$ to $25 \mathrm{deg}\left(\alpha_{2}\right)$, but further increase of bevel angle from $25\left(\alpha_{2}\right)$ to $30 \mathrm{deg}\left(\alpha_{3}\right)$ of cutter blade, resulted in increase of specific cutting energy with all selected levels of shear angle, approach angle and thickness of cutter blade, respectively. The specific cutting energy was lower for bevel angle at $25 \mathrm{deg}\left(\alpha_{2}\right)$ with $10\left(\mathrm{~T}_{3}\right) \mathrm{mm}$ thicknesses of cutter blade, at all selected levels of shear angle $(\theta)$ and approach angle $(\varphi)$.

Statistical Analysis of Specific Cutting Energy (SEC)

The statistical analysis of the data was performed, to assess the significance of the variables viz., thickness (T), 
bevel angle $(\alpha)$, shear angle $(\theta)$ and approach angle $(\varphi)$ on specific cutting energy (SEC). The analysis of variance on SEC is furnished in Table 2.

The result of ANOVA indicates that, there was a significant difference among the treatments. The individual effect of the variables viz., thickness $(T)$, approach angle $(\varphi)$ shear angle $(\theta)$ deg and bevel angle $(\alpha)$ deg of cutter blade on specific cutting energy (SEC) was significant, at 1 percent level of probability.

Table 2: ANOVA on Specific Cutting Energy

\begin{tabular}{|c|c|c|c|c|c|}
\hline Sl. No & SV & DF & SS & MS & $\mathbf{F}$ \\
\hline \multirow[t]{2}{*}{1} & Treatment & 107 & 12134.81 & 113.40 & $6.45 * *$ \\
\hline & Bevel angle of cutting blade $(\alpha)$ & 3 & 281.97 & 93.99 & $5.35 * *$ \\
\hline 2 & Thickness of blade $(\mathrm{T})$ & 2 & 1342.09 & 671.04 & $38.19 * *$ \\
\hline 3 & Shear angle of cutting blade $(\theta)$ & 2 & 2362.53 & 1181.27 & $67.24 * *$ \\
\hline 4 & Approach angle of cutting blade $(\varphi)$ & 2 & 2986.14 & 1493.07 & $84.99 * *$ \\
\hline 5 & $\alpha \times \mathrm{T}$ & 6 & 856.59 & 142.76 & $8.13 * *$ \\
\hline 6 & $\alpha \times \theta$ & 6 & 377.70 & 62.95 & $3.58 * *$ \\
\hline 7 & $\alpha \times \varphi$ & 6 & 153.03 & 25.50 & $1.45 * *$ \\
\hline 8 & $\mathrm{~T} \times \theta$ & 4 & 365.62 & 91.40 & $5.2032 * *$ \\
\hline 9 & $\mathrm{~T} \times \varphi$ & 4 & 53.69 & 13.42 & $0.76 * *$ \\
\hline 10 & $\theta \times \varphi$ & 4 & 892.77 & 223.19 & $12.70 * *$ \\
\hline 11 & $\alpha \times \mathrm{T} \times \theta$ & 12 & 266.91 & 22.24 & $1.26 * *$ \\
\hline 12 & $\alpha \times \mathrm{T} \times \varphi$ & 12 & 396.19 & 33.01 & $1.87 * *$ \\
\hline 13 & $\alpha \times \theta \times \varphi$ & 12 & 470.81 & 39.23 & $2.23 * *$ \\
\hline 14 & $\mathrm{~T} \times \theta \times \varphi$ & 8 & 330.83 & 41.35 & $2.35 * *$ \\
\hline 15 & $\alpha \times \mathrm{T} \times \theta \times \varphi$ & 24 & 997.89 & 41.58 & $2.36 * *$ \\
\hline \multirow[t]{2}{*}{16} & Err & 214 & 3759.34 & 17.56 & \\
\hline & Total & 428 & 28028.97 & & \\
\hline
\end{tabular}

$\mathrm{Cv}=1.82$ per cent $* *=$ Significant at $1 \%$ level

\section{Optimization of Levels of Variables with Impact Type Pendulum Test Rig}

The selected levels of variables were optimized, for achieving the best performance of cutter blade, in terms of minimum specific cutting energy with impact type pendulum test rig. The lowest mean value of specific cutting energy with different combination of the selected levels of variable, is furnished in Table 3.

Table 3: Optimized Values of Variables for Different Treatment Combination

\begin{tabular}{|c|c|c|}
\hline Parameter & $\begin{array}{c}\text { Treatment Combination Levels of Selected } \\
\text { Variables }\end{array}$ & Values \\
\hline Specific cutting energy & $\alpha_{2} \times T_{3} \times \theta_{1} \times \varphi_{2}$ & $178.04 \mathrm{~J}$ \\
\hline
\end{tabular}

Hence, the treatment combination of $\alpha_{2} \times \mathrm{T}_{3} \times \theta_{1} \times \varphi_{2}$ can be selected, as the optimized combination of selected variable (specific cutting energy was $178.04 \mathrm{~J}$ ) for designing a new shredder, or modification of the cutting mechanisms of shredder. 


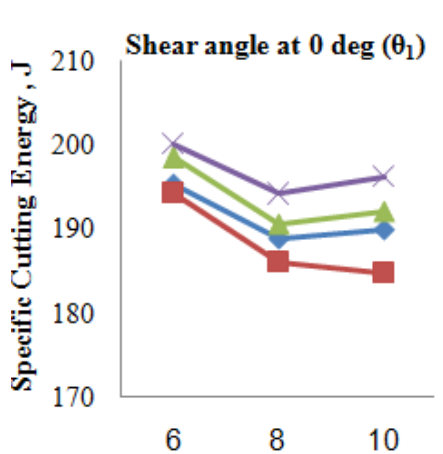

Thickness of cutter blade

(T) $\mathrm{mm}$

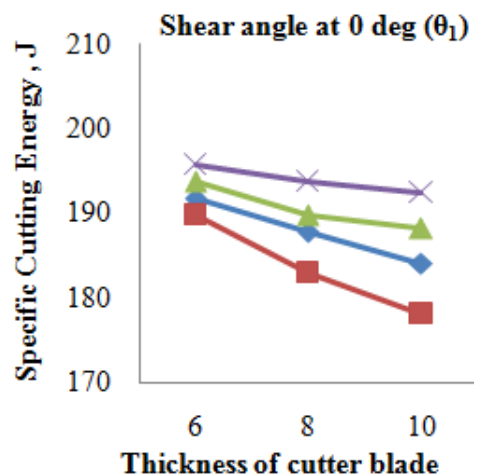

(T) $\mathrm{mm}$

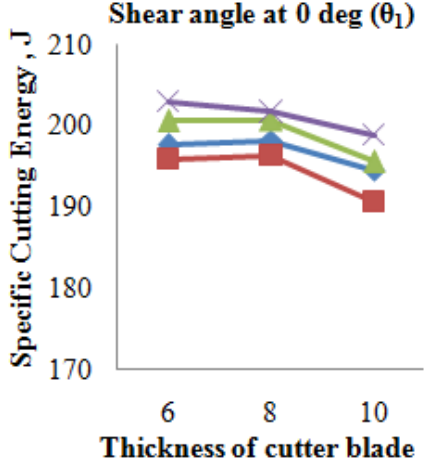

(T) $\mathrm{mm}$

$\longrightarrow \varphi 1$ with $\alpha 1-\varphi 1$ with $\alpha 2$

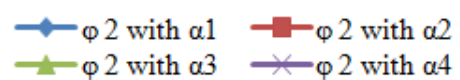

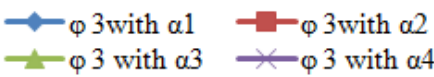

Figure 5(1): Effect of Thickness of Cutter Blade on Specific Cutting Energy for Cotton Stem at 0 Deg $\left(\theta_{1}\right)$ Shear Angle with Respect to Bevel Angle $(\alpha)$ and Approach Angle $0(\varphi)$

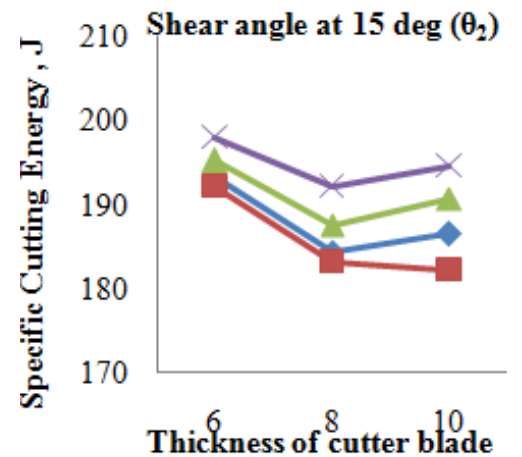

(T) $\mathbf{m m}$

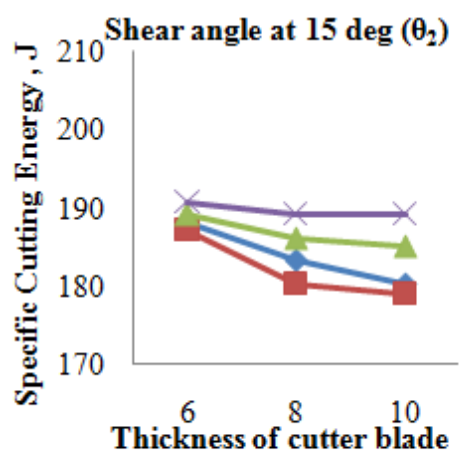

(T) $\mathrm{mm}$

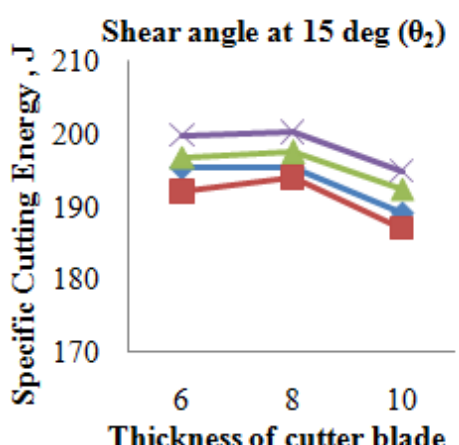

(T) $\mathrm{mm}$
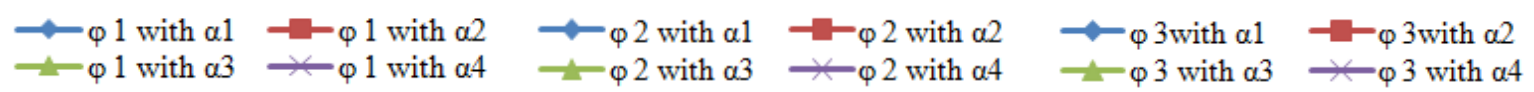

Figure 5(2): Effect of Thickness of Cutter Blade on Specific Cutting Energy for Cotton Stem at 15 $\operatorname{Deg}\left(\theta_{2}\right)$ Shear Angle with Respect to Bevel Angle $(\alpha)$ and Approach Angle $0(\varphi)$

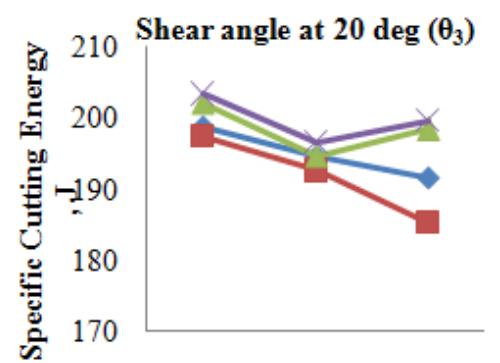

Thickness of cưtter blate (T) $\mathrm{mm}$

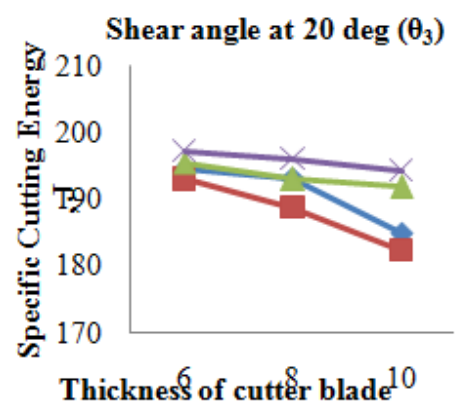

(T) $\mathrm{mm}$

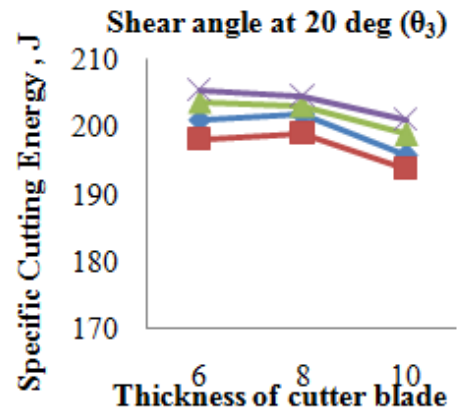

(T) $\mathrm{mm}$
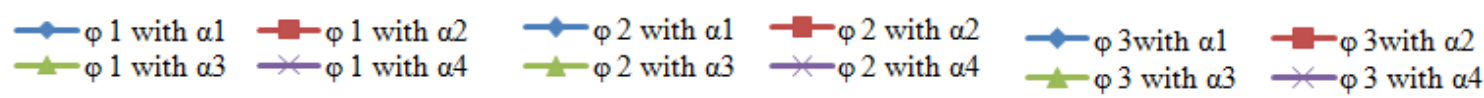

Figure 5(3): Effect of Thickness of Cutter Blade on Specific Cutting Energy for Cotton Stem at 20 Deg $\left(\theta_{3}\right)$ Shear Angle with Respect to Bevel Angle $(\alpha)$ and Approach Angle $0(\varphi)$ 

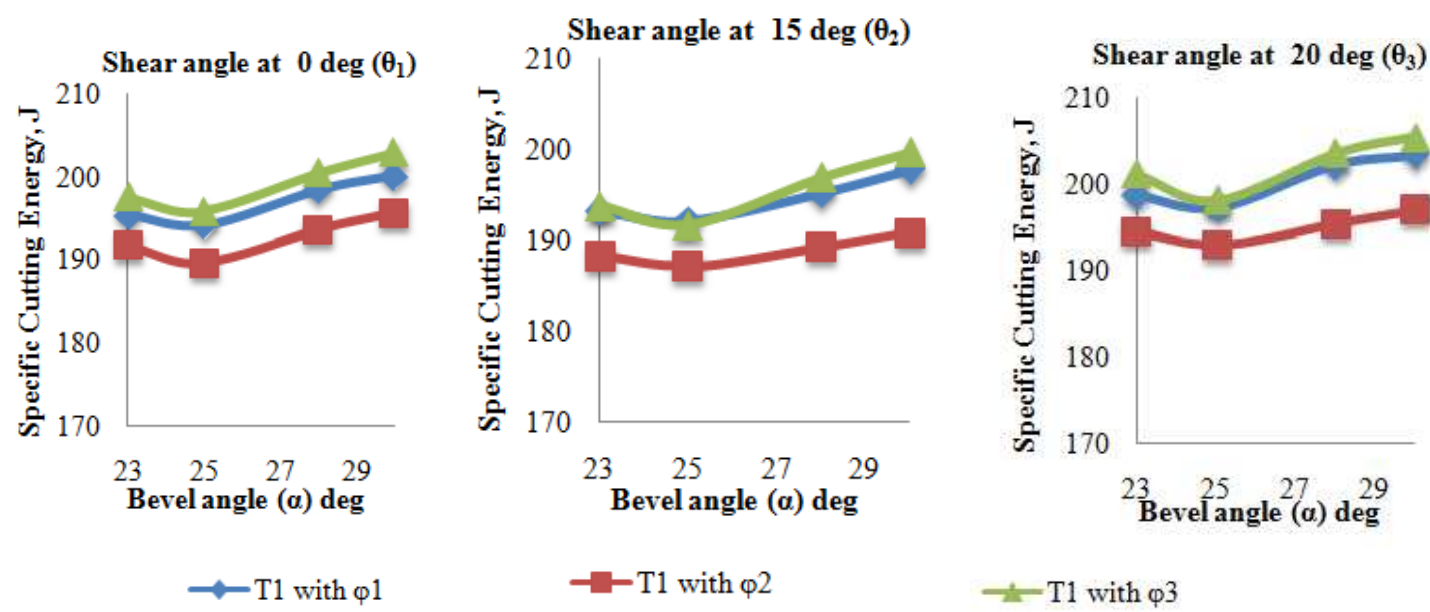

Figure 6(1): Effect of Bevel Angle (A) Deg of Cutter Blade on Specific Cutting Energy for Cotton Stem At 6 mm $\left(T_{1}\right)$ Thickness of Cutter Blade with Respect to Shear Angle $(\Theta)$ and Approach Angle $0(\Phi)$
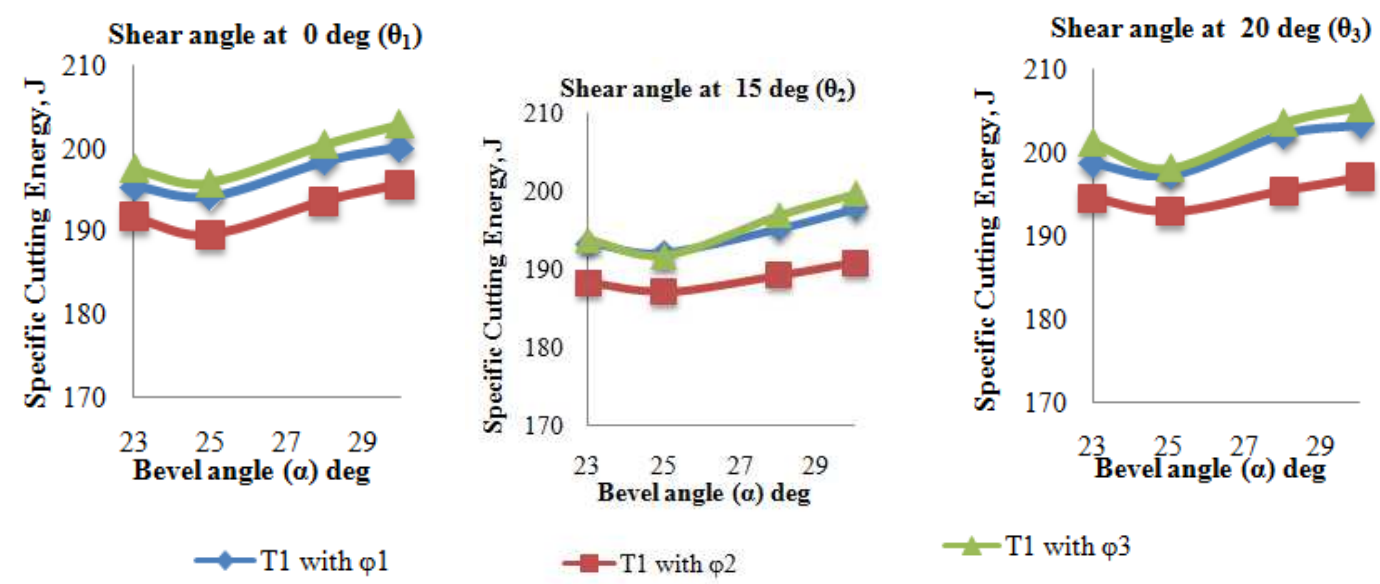

Figure 6(2): Effect of Bevel Angle (A) Deg of Cutter Blade on Specific Cutting Energy for Cotton Stem at

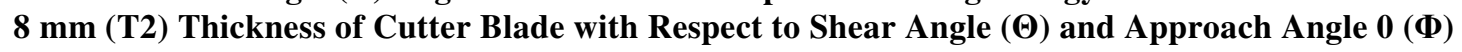
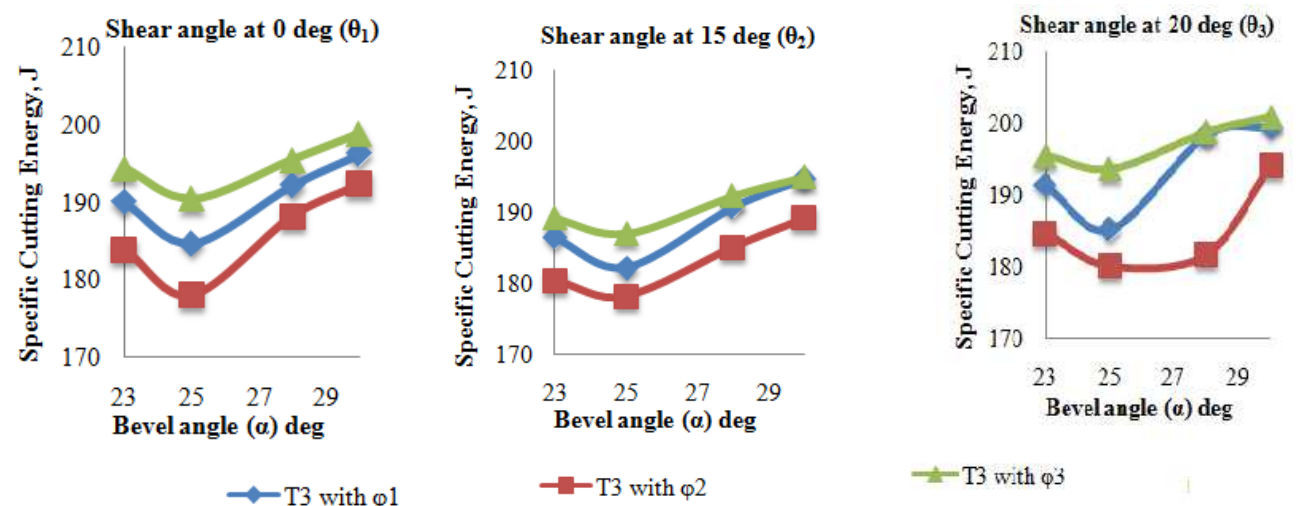

Figure 6(3): Effect of Bevel Angle Deg of Cutter Blade on Specific Cutting Energy for Cotton Stem at 10 mm (T $\left.\mathbf{T}_{3}\right)$ Thickness of Cutter Blade with Respect to Shear Angle $(\Theta)$ and Approach Angle $0(\Phi)$

\section{Performance Evaluation of Modified Shredder}

Modified shredder was evaluated in cotton fields, with a forward speed of operation 2 to $5 \mathrm{~km} \mathrm{~h}^{-1}$ and the peripheral velocity of cutter blade $28 \mathrm{~m} \mathrm{~s}^{-1}$, respectively. The observation on shredding efficiency, in terms of length of cut 
of crop residues at different scale level $\left(\mathrm{L}_{1}\right.$ to $\left.\mathrm{L}_{5}\right)$, was recorded during field evaluation. The view of the trial field, during and after shredding operation are done, as shown in Plate 3
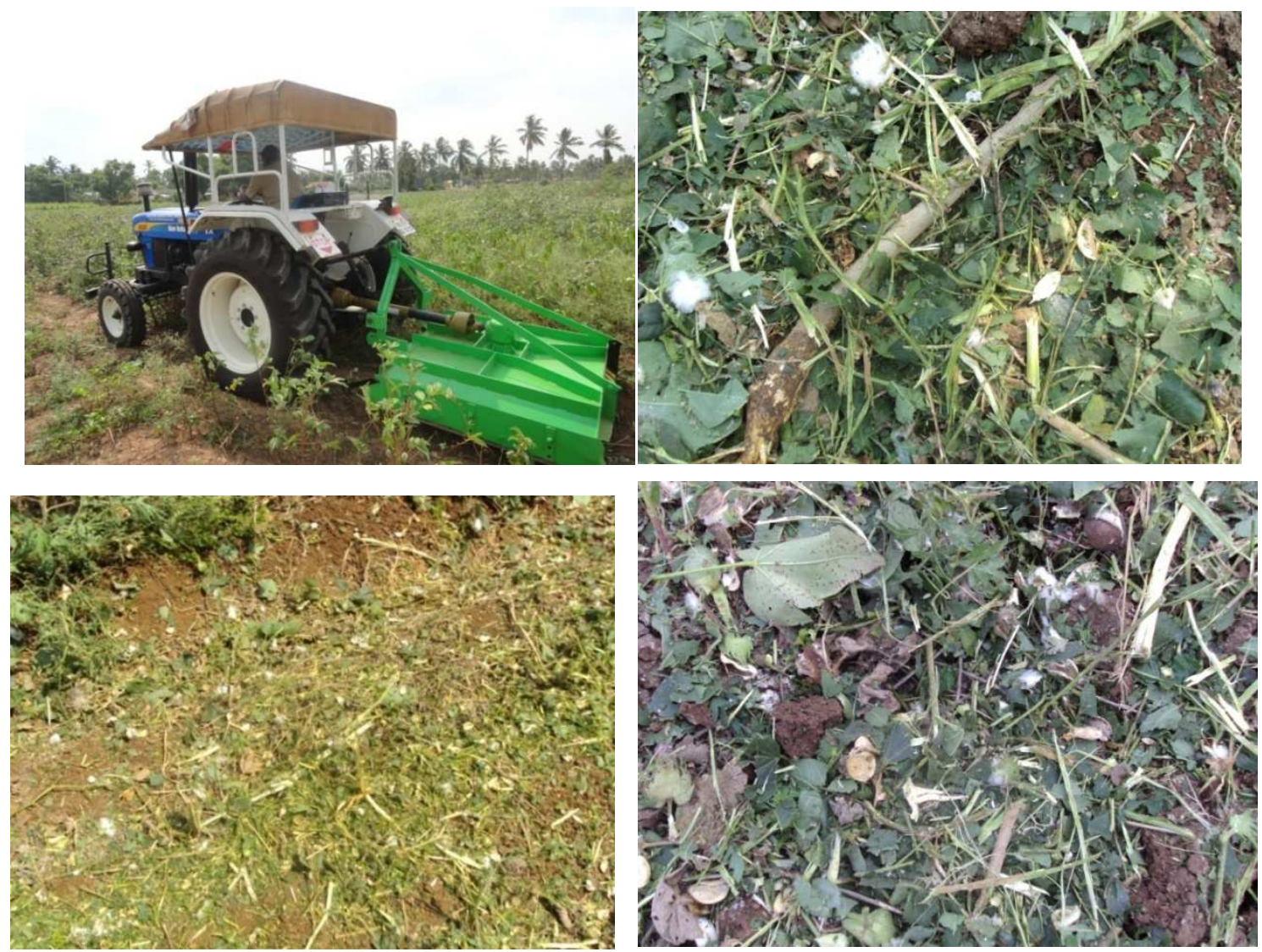

Plate 3: Field Experiments of Shredder with Selected Levels of Variables

The observation on shredding efficiency, field capacity and time consumed were observed during the evaluation. The result of field evaluation of prototype tractor operated modified Shredder is furnished in Table 4.

Table 4: Result of Performance Evaluation of Modified Shredder

\begin{tabular}{|c|l|c|}
\hline Sl. No & \multicolumn{1}{|c|}{ Items } & Prototype \\
\hline 1 & Location & Farmer field, Coimbatore \\
\hline 2 & Variety of cotton & KC $_{1}$ \\
\hline 3 & Diameter of cotton stem, mm & 12 to 17 \\
\hline 4 & Moister content of cotton at the time of shredding d.b \% $^{-1}$ & 44.21 \\
\hline 5 & Operation cost Rs ha $^{-1}$ & 2654.65 \\
\hline 6 & ${\text { Time required to cover ha } \mathrm{h}^{-1}}^{-1}$ & 5.29 \\
\hline 7 & Width of operation, $\mathrm{m}^{\prime}$ & 1.10 \\
\hline 8 & Number of un cut cotton stem in row 100 m length $^{-1}$ & 2 \\
\hline 9 & Theoretical field capacity, ha $\mathrm{h}^{-1}$ & 0.24 \\
\hline 10 & Actual field capacity ha $\mathrm{h}^{-1}$ & 0.196 \\
\hline 11 & Field efficiency, $\%$ & 81.66 \\
\hline 12 & Shredding efficiency, $\%$ & 92 \\
\hline
\end{tabular}

The length of cut of crop stem at different forward speed of operation from 2 to $5 \mathrm{~km} \mathrm{~h}^{-1}$ with a constant peripheral velocity of cutter blade $28 \mathrm{~m} \mathrm{~s}^{-1}$ as shown in Figure 5. 


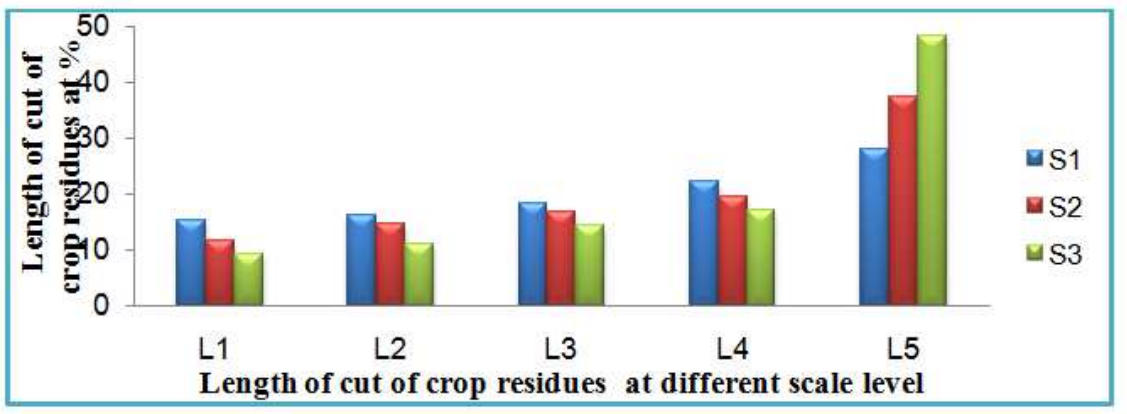

Figure 7: Length of Cut of Crop Stem at Different Forward Sped of Operation

The modified shredders resulted in 37.55 and 82 percent savings, in cost and time of operation, respectively, when compared to conventional method of crop residue removing in agricultural field.

\section{CONCLUSIONS}

The following conclusions were obtained from the experiments:

- The lowest specific cutting energy $178.04 \mathrm{~J}$ was observed in treatment combination of 15 deg $\left(\varphi_{2}\right)$ approach angle, $0 \mathrm{deg}\left(\theta_{1}\right)$ shear angle, $25 \mathrm{deg}$ bevel angle $\left(\alpha_{2}\right)$ with $10 \mathrm{~mm}\left(\mathrm{~T}_{3}\right)$ thickness of cutter blade. This combination has been selected, for modifying the cutting mechanism of shredder.

- The actual field capacity, theoretical field capacity, field efficiency and shredding efficiency of the modified shredder were $0.24,0.196$ ha $^{-1}, 81.66$ and 92 percent observed, during the field evaluation.

- The modified shredder saves in 37.55 and 82 percent cost and time, when compared with conventional method of crop residue removal.

\section{REFERENCES}

1. Chancellor, W.J. (1958). Energy requirement for cutting forage. Journal of Agri. Eng. 30(10):633-636.

2. Chattopadhyay, P.S. and Pandey, K.P. (1999). Effect of knife and operational parameters on energy requirement in fail forage harvesting. J. agric. Engg. Res., 23(1):3-12.

3. Church, M., J.F. Wolcott and W.K. Fletcher. 1991. A test of equal mobility in fluvial sediment transport: Behaviour of the sand fraction. Water Res. Res. 27(11): 2941-2951

4. EL-Sahar, E.A., 1988. Design of harvester appropriate for Egyptian. MSe. Thesis. Fac. of Ag. Ain Shams Univ. Egypt.

5. Eshaghbeygi A, Hoseinzadeh B, Khazaei M, Masoumi AA (2009) Bending and shearing properties of wheat stem of Alvand variety. World Appl Sci J 6(8): 1028-1032.

6. Godesa T (2004) Determination of minimal cutting speed by flailing potato vines. Act Agr Scand 83 - 1 .

7. Hoseinzadeh B, Eshaghbeygi A, Raghami $N$ (2009) Effect of moisture content, bevel angle and cutting speed on shearing energy of three wheat varieties. World Appl Sci J 7(9):1120-1123.

8. Imababi, A.T. 1992. Design and development of rotary harvester for harvesting sesame crop. Ph. D. Thesis Ag. Eng. Dept., Fac. of Ag. Cairo Univ. Eygpt.

9. Jelani, A.R., D. Ahmad, A. Hitam, A. Yahya, and J. Jamak. 1999. Reaction force and energy requirement for cutting oil palm fronds by spring powered sickle cutter. Journal of Oil Palm Research. 11(2), 114-122. 
10. Johnson, P.C., C.L. Clementson, S. K. Mathanker, T.E. Grift and A.C. Hansen. 2012. Cutting energy characteristics of Miscanthus $X$ giganteus stems with varying oblique angle and cutting speed. Biosystems engineering. 112(1): 42-48.

11. Koloor, R.T, and G. Kiani. 2007. Soybean stems cutting energy and the effects of blade parameters on it. Pakistan Journal of Biological sciences.10(9):1532-1535.

12. Lee SW, Huh YK (1984) Threshing and cutting forces Korean rice. Trans ASAE 27: 1954-1957

13. Luis, F.C.; G. M. Savage; L. L. Eggerth and G. G. Clarence 1993.Composting and Recycling Municipal Solid Waste. Lewis Pub.London. P: 453-468.

14. Maughan, J.D., M. Brian Fehrenbacher., S. K. Mathanker., T. E. Grift and A.C. Hansen. 2012. Impact of Cutting Speed, Blade Type, and Blade Angle on Miscanthus harvesting Energy Requirement. An ASABE Meeting Presentation.12-1338182.

15. Mehta, H. (2004). Bioconversion of Different Wastes for Energy Options, Sardar Patel Renewable Energy Research Institute Vallabh Vidyanagar, ppt.

16. Mesquita CM, Hanna MA (1995) physical and mechanical properties of soybean crops. Trans ASABE 38(6): 16551658.

17. Morad and Fouda 2009. Energy and cost required for removing residues of some field crops using different implements Egypt.J. og Appl. Sci., 24(3).

18. Muller Z (1988) An investigation of mechanical and geometrical properties influencing the stability of wheatstalk. Physical Properties of Agricultural Materials and Products, Edited by R Reznicek. Washington: Hemisphere Publishing Corporation.

19. Nazari Galedar M, Tabatabaeefar A, Jafari A, Sharifi A, Rafiee S (2008) Bending and shearing characteristics of alfalfa stems. CIGR Ejournal, Manuscript FP 08 001. Vol.X.

20. Niveta Jain, Arti Bhatia, Himanshu Pathak (2014) Emission of Air Pollutants from Crop Residue Burning in India - Centre for Environment Science and Climate Resilient Agriculture, Indian Agricultural Research Institute, New Delhi- 110012, India

21. O'Dogherty, M.J. and Gale, G. E. (1986). Laboratory studies of the cutting of grass stems. J. agric. Engg. Res., 35(3):115129.

22. Pathak, B.S. (2006). Crop Residue to Energy, In Environment and Agriculture, Chadha, K.L. and Swaminathan, M.S. (Eds.), Malhotra Publishing House, New Delhi, p. 854-869.

23. Pathak, H., Bhatia, A., Jain, N. and Aggarwal, P.K. (2010). Greenhouse Gas Emission and Mitigation in Indian AgricultureA Review, In ING Bulletins on Regional Assessment of Reactive Nitrogen, Bulletin No. 19, (Ed. Bijay-Singh), SCON-ING, New Delhi, p. $i-i v, 1-34$.

24. Pathak, H., Singh, R., Bhatia, A. and Jain, N. (2006). Recycling of Rice Straw to Improve Wheat Yield and Soil Fertility and Reduce Atmospheric Pollution. Paddy Water Environ. 4: 111-117.

25. Persson, S.1987.Mechanics of cutting Plant Materials 62, 102,105.St. Joseph, Mich. ASAE.

26. Prasad, J. and Gupata, C.P. (1975). Mechanical properties of maize stalk in relation to harvesting. J. agric. Engg. Res., 20 (2): 79-87.

27. Prasad,J. and C.P. Gupta. 1975. Mechanical properties of maize stalk as related to harvesting. J.of Agric. Eng. Res.

28. Rajendra Reddy, G., G.U. Male war and B.G. Karle. 2002. Effect of crop residue incorporation and tillage operations on soil properties of vertisol under rainfed agriculture. Indian J. Dryland Agric. Res. \& Dev., 17(1): 5-58.

29. Reza, T.K.2007.Paddy stems cutting energy and suggested blade as related to harvesting. J. of Agric. Eng. Res.20:79-87. 
30. Senthilkumar, T. 2004. Investigation on development of a tractor operated cotton stalk shredder cum insitu applicator as influenced by crop, machine and operational parameters PhD Thesis. Department of farm Machinery, Tamil Nadu Agricultural University, Coimbatore, India.

31. Tavakoli H, Mohtasebi SS, Jafari A (2009) Effects of moisture content inter node position and loading rate on the bending characteristics of barely straw. Res Agr Eng 55(2): 45-51.

32. Vagadia, V.R., R.K.Kathiria and J.B.Savani,2004. Design and development of agricultural wastes shredder a new concept.Paper presented at the XXXVIII Annual convention of ISAE, held at College of agricultural Engineering and Technology, Dr. BSKKV, Dapoli, January, 16-18.

33. Yiliep, Y.D. and U.S. Mohammed, 2005.Effect of knife velocity on cutting energy and efficiency during impact cutting of sorghum stalk. The E-Journal of CIGR, Vol. VII: Manuscript PM 05004.

34. Yumnam Jekendra and Pratap Singh, 1991. Energetic of forge chopping. Agricultural Mechanization in Asia, Africa and Latin America.22 (1):59-63. 